\title{
Sibling and parental history in type 2 diabetes risk among ethnic Chinese: the Chin-Shan Community Cardiovascular Cohort Study
}

\author{
Kuo-Liong Chien ${ }^{\mathrm{a}, \mathrm{c}}$, Hsiu-Ching Hsuc ${ }^{\mathrm{c}}$, Ta-Chen Suc ${ }^{\mathrm{c}}$, Wei-Tien Chang ${ }^{\mathrm{d}}$, \\ Pei-Chun Chen ${ }^{b}$, Ming-Fong $\mathrm{Chen}^{\mathrm{c}}$ and Yuan-Teh Lee ${ }^{\mathrm{c}}$
}

Institutes of ${ }^{a}$ Preventive Medicine, ${ }^{b}$ Environmental Medicine, College of Public Health, National Taiwan University, Departments of ${ }^{\mathrm{C}}$ Internal Medicine and ${ }^{\mathrm{d}}$ Emergency Medicine, National Taiwan University Hospital, Taipei, Taiwan

Received 10 November 2007 Accepted 9 July 2008

Background This study aims to compare various family history profiles as predictors of diabetes in a community-based prospective cohort because few prospective studies have examined the association of family history with diabetes risk in ethnic Chinese populations.

Methods Among 2960 participants free from baseline diabetes through the Chin-Shan Community Cardiovascular Cohort Study, there were 548 cases that developed diabetes after a median $\mathbf{9}$ years of follow-up.

Results After multivariate adjustment, sibling history was associated with diabetes [Relative risk (RR): 2.08, 95\% confidence interval $(\mathrm{Cl}): 1.42-3.06, P=0.0002]$. Both maternal and paternal histories had similar effects (RR: 1.62, 95\% $\mathrm{Cl}$ : 1.04-2.51 for paternal history, RR: $1.36,95 \% \mathrm{Cl}$ : 0.98-1.89 for maternal history). Obese participants with sibling history increased the risk of diabetes by 4.6 -fold (RR: $4.61,95 \% \mathrm{Cl}$ : $2.93-7.26$ ), compared with those with neither obesity nor family history.

Conclusion The findings support the hypothesis that sibling history is more important than parental history for diabetes risk. Eur J Cardiovasc Prev Rehabil 15:657-662 (c) 2008 The European Society of Cardiology

European Journal of Cardiovascular Prevention and Rehabilitation 2008, 15:657-662

Keywords: Chinese, cohort, diabetes, family history

\section{Introduction}

Health burdens and growing epidemics of type 2 diabetes mellitus have made primary prevention crucial in health promotion [1,2]. This involves early identification of risk factors. Although diabetes is a complex disease involving a combination of genetic and environmental factors, it is useful to utilize family history as a screening tool. Family history represents not only valuable genetic information but also common environmental component factors [3,4]. Owing to its self-reported characteristic, data on family history is relatively inexpensive and easy to collect, and a positive family history provides clues regarding the complexities of gene-gene and gene-environmental

Correspondence to Professor Yuan-Teh Lee, Department of Internal Medicine National Taiwan University Hospital, No. 7, Chung-Shan S. RD, 100, Taipei, Taiwan Tel: +886 23322 8017; fax: + 88622392 0456;

e-mail: ytlee@ha.mc.ntu.edu.tw

1741-8267 (C) 2008 The European Society of Cardiology interactions that help identify the subsets of populations at risk $[5,6]$.

First-degree relatives of patients with diabetes have a five-fold risk of developing diabetes in the adult US population [7]. A self-reported positive familial risk of diabetes could identify $73 \%$ of people as patients with diabetes and correctly predicted more than one-fourth of prevalent cases [8]. Nonetheless, different family history profiles, including maternal, parental, and sibling histories, have been proven to have different impacts on certain subclinical diseases [9]. Very few prospective studies have compared their roles on diabetes. Using prospective design to study family history and diabetes risk could prevent information bias and provide valid inference. Therefore, this prospective cohort study on asymptomatic healthy ethnic Chinese population was 
conducted to test the role of family history on diabetes risk. We hypothesized that different family histories had varying effects on diabetes risk among Chinese.

\section{Methods}

\section{Study design and participants}

Details of this cohort study have been published previously [10-12]. Briefly, the Chin-Shan Community Cardiovascular Cohort Study began in 1990 by recruiting 3602 individuals aged 35 years old and above, homogenous in Chinese ethnicity, in the Chin-Shan township. The participants were invited to undertake standard procedures of physical examination, blood sampling, and clinical measurements at a local site. Information about anthropometry, lifestyle, and medical conditions was assessed by an interview questionnaire in 2-year cycles. The validity and reproducibility of the collected data and measurements have been reported in detail elsewhere [11]. The participants undertook clinical measurements such as echocardiography and carotid sonography by cardiologists.

Among the 3602 participants, we excluded missing baseline data on blood sampling $(n=41)$, diagnosis of diabetes (fasting glucose $\geq 126 \mathrm{mg} / \mathrm{dl}$ or with hypoglycemic medication history) $(n=473)$, and cardiovascular disease and cancer history $(n=170)$. We followed the remaining 2960 participants regularly and checked their medical history and medication on biennial intervals. The response rate was $85.7 \%$ by the end of the study. The National Taiwan University Committee Review Board approved the study protocol.

\section{Definition of family history}

Family history was defined in the questionnaires and the participants were asked if their biological parents or siblings had diabetes. The number of siblings was also recorded. We categorized the study participants into four family history groups: sibling, paternal and maternal history, and no family history.

\section{Laboratory measurements}

All venous blood samples drawn after a 12 -h overnight fast were immediately refrigerated. Blood samples for glucose analysis were drawn into glass test tubes each containing $80 \mathrm{~mol} / \mathrm{l}$ fluoride/oxalate reagent. After centrifugation at $1500 \mathrm{~g}$ for $10 \mathrm{~min}$, glucose levels were measured by enzymatic assay (Merck 3389 commercial kit; Darmstadt, Germany) in an Eppendorf 5060 autoanalyzer. Plasma insulin level was determined using the ELISA method.

\section{Diagnosis of type 2 diabetes}

Type 2 diabetes was defined by the presence of at least one of the following criteria: (i) a fasting glucose concentration more than or equal to $126 \mathrm{mg} / \mathrm{dl}$ and (ii) treatment with the hypoglycemic medication (insulin or oral hypoglycemic agents). The diagnostic criteria were consistent with those proposed by the American Diabetes Association [1].

\section{Statistical analysis}

Categorical variables were presented as contingency tables with the $\chi^{2}$ test used to test the difference across family histories. The continuous variables were presented by mean and standard deviation and analyzed by analysis of variance. Diabetes incidence rates were calculated by person-year methods and stratified by various family histories, and we treated no family history as the control group.

The association between family history and risk of diabetes was analyzed by the Cox regression model, adjusting for potential confounding factors. Three Cox models were specified to evaluate the adjusted relative risks of family history status: model 1 was adjusted for age groups (35-44, 45-54, 55-64, 65-74, $\geq 75$ years old) and sex. Model 2 was additionally adjusted for body mass index (BMI) $(<18,18-20.9,21-22.9,23-24.9$, or $\geq 25 \mathrm{~kg} / \mathrm{m}^{2}$ ). Model 3 included additional confounding factors such as smoking (yes/no or abstinence), current alcohol drinking (regular/no), marital status (single, married and living with spouse, or divorced and separate), education level (less than 9 years, at least 9 years), occupation (no work, labor, official or business), and regular exercise (yes/no). The models' goodness-offit was tested using the Hosmer and Lemeshow test [13] and the model was acceptable in Model $3(P=0.12)$.

We estimated the two joint effects of family history with age (cutoff by 65 years old) and high BMI (cutoff by median value, $23 \mathrm{~kg} / \mathrm{m}^{2}$ ), and categorized the exposed factors into various categories. All of the statistical tests were two-tailed and probability values less than 0.05 were considered statistically significant. Analyses were performed with SAS version 9.1 (SAS Institute, Cary, North Carolina, USA) and Stata version 9.1 (Stata Corp., College Station, Texas, USA).

\section{Results}

Of the 2960 participants without diabetes at baseline, 89 had sibling history, 73 had paternal history, and 163 had maternal history of diabetes. Participants with different baseline family histories were similar in sex, BMI, lifestyle habits (e.g. smoking, alcohol drinking, marital status, regular exercise), and hypertension status. Individuals with paternal history were more likely to have higher education levels and white-collar jobs (Table 1). For baseline continuous variables, participants across different family histories had similar waist, waist-hip ratio, fasting, and post-challenge insulin and lipid profiles 
Table 1 Distribution of various baseline demographic, lifestyle, and socioeconomic factors in the study population in the CCCC cohort (1990-1991), specified by family history patterns

\begin{tabular}{|c|c|c|c|c|c|c|c|c|c|}
\hline & $\begin{array}{c}\text { No history } \\
N=2635(\%)\end{array}$ & & $\begin{array}{c}\text { Mother } \\
N=163(\%)\end{array}$ & & $\begin{array}{c}\text { Father } \\
N=73(\%)\end{array}$ & & $\begin{array}{c}\text { Sibs } \\
N=89(\%)\end{array}$ & & $P$ \\
\hline Sex & & & & & & & & & 0.34 \\
\hline Men & 46.6 & & 54.0 & & 48.0 & & 46.1 & & \\
\hline Women & 53.4 & & 46.0 & & 52.1 & & 53.9 & & \\
\hline BMI $\left(\mathrm{kg} / \mathrm{m}^{2}\right)$ & & & & & & & & & 0.10 \\
\hline$<18$ & 3.9 & & 2.5 & & 0.0 & & 4.5 & & \\
\hline 18 to 20.9 & 21.4 & & 19.6 & & 15.3 & & 15.7 & & \\
\hline 21 to 22.9 & 25.8 & & 22.1 & & 30.6 & & 23.6 & & \\
\hline 23 to 24.9 & 21.4 & & 24.5 & & 12.5 & & 21.4 & & \\
\hline$\geq 25$ & 27.5 & & 31.3 & & 41.7 & & 34.8 & & \\
\hline Current smoker (yes) & 35.8 & & 36.8 & & 35.6 & & 37.1 & & 0.99 \\
\hline Alcohol drinking (yes) & 29.7 & & 25.2 & & 35.6 & & 32.6 & & 0.36 \\
\hline Marital status & & & & & & & & & 0.32 \\
\hline Single & 2.9 & & 1.2 & & 1.4 & & 3.4 & & \\
\hline Lived with spouse & 86.4 & & 92.0 & & 93.2 & & 85.2 & & \\
\hline Divorced or separate & 10.7 & & 6.8 & & 5.5 & & 11.4 & & \\
\hline Education level & & & & & & & & & $<0.0001$ \\
\hline$<9$ years & 94.4 & & 93.3 & & 79.5 & & 94.4 & & \\
\hline$\geq 9$ years & 5.6 & & 6.8 & & 20.6 & & 5.6 & & \\
\hline Job status & & & & & & & & & $<0.0001$ \\
\hline No job & 50.1 & & 28.8 & & 26.0 & & 39.3 & & \\
\hline Blue collar & 35.1 & & 47.9 & & 42.5 & & 31.5 & & \\
\hline White collar & 14.8 & & 23.3 & & 31.5 & & 29.2 & & \\
\hline Regular exercise habit (yes) & 14.8 & & 12.3 & & 9.6 & & 13.5 & & 0.51 \\
\hline \multirow[t]{2}{*}{ Hypertension } & 27.2 & & 20.5 & & 19.2 & & 32.6 & & 0.07 \\
\hline & Mean & SD & Mean & SD & Mean & SD & Mean & SD & \\
\hline Age, year & 54.6 & 12.4 & 47.9 & 8.9 & 46.1 & 9.0 & 53.2 & 11.6 & $<0.0001$ \\
\hline BMI $\left(\mathrm{kg} / \mathrm{m}^{2}\right)$ & 23.2 & 3.3 & 23.7 & 3.3 & 24.2 & 3.3 & 23.8 & 3.4 & 0.009 \\
\hline Waist $(\mathrm{cm})$ & 82.4 & 9.8 & 83.8 & 9.6 & 83.5 & 9.7 & 83.5 & 8.7 & 0.36 \\
\hline Waist-hip ratio & 0.89 & 0.07 & 0.90 & 0.06 & 0.90 & 0.06 & 0.90 & 0.06 & 0.78 \\
\hline Fasting insulin $(I \mathrm{U} / \mathrm{ml})^{\mathrm{a}}$ & 1.51 & 0.91 & 1.70 & 0.77 & 1.54 & 0.77 & 1.72 & 0.79 & 0.07 \\
\hline Fasting glucose $(\mathrm{mg} / \mathrm{dll})^{\mathrm{a}}$ & 4.61 & 0.10 & 4.64 & 0.09 & 4.64 & 0.11 & 4.61 & 0.09 & 0.001 \\
\hline Systolic BP $(\mathrm{mmHg})^{\mathrm{a}}$ & 4.81 & 0.15 & 4.78 & 0.14 & 4.78 & 0.14 & 4.82 & 0.15 & 0.030 \\
\hline Diastolic BP $(\mathrm{mmHg})^{a}$ & 4.33 & 0.14 & 4.32 & 0.12 & 4.33 & 0.15 & 4.32 & 0.16 & 0.92 \\
\hline Total cholesterol $(\mathrm{mg} / \mathrm{dl})^{\mathrm{a}}$ & 5.25 & 0.22 & 5.25 & 0.23 & 5.26 & 0.23 & 5.21 & 0.23 & 0.33 \\
\hline Triglyceride $(\mathrm{mg} / \mathrm{dl})^{\mathrm{a}}$ & 4.58 & 0.55 & 4.61 & 0.47 & 4.68 & 0.57 & 4.63 & 0.54 & 0.38 \\
\hline HDL-C $(\mathrm{mg} / \mathrm{dl})^{\mathrm{a}}$ & 3.85 & 0.26 & 3.83 & 0.25 & 3.83 & 0.24 & 3.78 & 0.25 & 0.11 \\
\hline LDL-C $(\mathrm{mg} / \mathrm{dll})^{\mathrm{a}}$ & 4.85 & 0.33 & 4.87 & 0.33 & 4.87 & 0.33 & 4.82 & 0.33 & 0.81 \\
\hline
\end{tabular}

BMI, body mass index; BP, blood pressure; CCCC, Chin-Shan Community Cardiovascular Cohort; HDL-C, high-density lipoprotein-cholesterol; LDL-C, low-density lipoprotein-cholesterol. a Geometric mean.

(i.e. total cholesterol, triglyceride, HDL, and LDL cholesterol). Individuals with parental history tended to be younger with lower systolic blood pressure, higher BMI, and higher fasting glucose levels.

For the follow-up cohort from 1990-1991 to the end of 2001 (median: 9 years, interquartile range: 4.2-9.3 years), there were 548 cases that developed diabetes. The incidence rates were the highest among individuals with sibling history (48.7/1000 person-years) compared with those with parental history (38 for paternal history and 34.2 for maternal history) (Table 2). After multivariate adjustment, sibling history was significantly associated with diabetes [RR: 2.08, 95\% confidence interval (CI): 1.42-3.06, $P=0.0002]$. Both paternal and maternal histories had similar effects on diabetes (RR: 1.62, 95\% CI: 1.04-2.51 for paternal history, RR: 1.36 , 95\% CI: 0.98-1.89 for maternal history). Subgroup analysis showed that only sibling history was significantly related to further diabetes in both sexes.
In mutually adjusted models, sibling history remained a significant and strong risk factor for diabetes (RR: 1.82, 95\% CI: $1.23-2.69, P=0.003)$, whereas paternal and maternal histories became nonsignificant (mother history: RR: $1.29,95 \%$ CI: $0.95-1.75, P=0.10$; father history: RR: $1.27,95 \%$ CI: $0.84-1.94, P=0.26)$. We also performed the subset selection strategy to determine the best predictive variables for diabetes risk. The results showed only sibling history remained in the best-fit model to predict diabetes (RR: $1.88,95 \%$ CI: $1.28-2.75$, $P=0.0012)$.

Patterns varied in the presence or absence of high BMI values (Fig. 1). Individuals with high BMI (BMI $\geq 23$ ) had consistently higher (by 1 -fold) risk of diabetes than individuals with lower BMI $(<23)$ regardless of family history. Participants with sibling history as well as high BMI values had a 4.6-fold higher risk of diabetes (RR: 4.61, 95\% CI: 2.93-7.26) compared with those with neither obesity nor family history. No significant multi- 
Table 2 Incidence rates (/1000 person-years) and relative risks [95\% confidence intervals (Cls) and significant levels] of diabetes incidence during 9 years of follow-up according to baseline family history categories in the study population

\begin{tabular}{|c|c|c|c|c|c|c|c|c|c|c|}
\hline & $\begin{array}{c}\text { No } \\
N=2635\end{array}$ & $\begin{array}{l}\text { Mother } \\
N=163\end{array}$ & & & $\begin{array}{l}\text { Father } \\
N=73\end{array}$ & & & $\begin{array}{c}\text { Sibs } \\
N=89\end{array}$ & & \\
\hline Cases & 457 & 41 & & & 22 & & & 28 & & \\
\hline Person-years & 18435.9 & 1199.5 & & & 578.7 & & & 575.1 & & \\
\hline \multirow[t]{2}{*}{ Rate $^{\mathrm{a}}$} & 24.8 & 34.2 & & & 38.0 & & & 48.7 & & \\
\hline & & $\mathrm{RR}$ & $95 \% \mathrm{Cl}$ & $P$ & $\mathrm{RR}$ & $95 \% \mathrm{Cl}$ & $P$ & $\mathrm{RR}$ & $95 \% \mathrm{Cl}$ & $P$ \\
\hline Model 1 & 1 & 1.40 & $(1.01-1.93)$ & 0.043 & 1.61 & $(1.04-2.48)$ & 0.031 & 2.05 & $(1.40-3.00)$ & 0.0002 \\
\hline Model 2 & 1 & 1.34 & $(0.97-1.85)$ & 0.076 & 1.47 & $(0.95-2.26)$ & 0.083 & 1.95 & $(1.33-2.87)$ & 0.001 \\
\hline Model 3 & 1 & 1.36 & $(0.98-1.89)$ & 0.065 & 1.62 & $(1.04-2.51)$ & 0.032 & 2.08 & $(1.42-3.06)$ & 0.0002 \\
\hline \multicolumn{11}{|l|}{ Men } \\
\hline Model $1^{b}$ & 1 & 1.52 & $(1.00-2.29)$ & 0.049 & 1.46 & $(0.82-2.58)$ & 0.20 & 1.92 & $(1.09-3.36)$ & 0.023 \\
\hline Model $2^{b}$ & 1 & 1.40 & $(0.92-2.14)$ & 0.12 & 1.75 & $(0.99-3.12)$ & 0.06 & 2.06 & (1.17-3.62) & 0.013 \\
\hline Model $3^{b}$ & 1 & 1.43 & $(0.94-2.19)$ & 0.10 & 1.55 & $(0.87-2.76)$ & 0.14 & 1.92 & $(1.09-3.39)$ & 0.024 \\
\hline \multicolumn{11}{|l|}{ Women } \\
\hline Model $1^{\mathrm{b}}$ & 1 & 1.15 & $(0.68-1.95)$ & 0.60 & 1.43 & $(0.73-2.80)$ & 0.29 & 2.00 & $(1.18-3.39)$ & 0.010 \\
\hline Model $2^{b}$ & 1 & 1.23 & $(0.72-2.08)$ & 0.45 & 1.43 & $(0.73-2.82)$ & 0.30 & 2.11 & $(1.24-3.58)$ & 0.006 \\
\hline Model $3^{b}$ & 1 & 1.17 & $(0.69-1.98)$ & 0.56 & 1.37 & $(0.70-2.68)$ & 0.36 & 2.02 & (1.18-3.44) & 0.010 \\
\hline
\end{tabular}

Model 1: adjusted for age groups $(35-44,45-54,55-64,65-74, \geq 75$ years old) and sex. Model 2: model 1 plus body mass index $(<18,18-20.9,21-22.9$ 23-24.9, or $\geq 25 \mathrm{~kg} / \mathrm{m}^{2}$ ). Model 3: model 2 plus smoking (yes/no or abstinence), current alcohol drinking (regular/no), marital status (single, married and living with spouse, or divorced and separate), education level (less than 9 years, at least 9 years), occupation (no work, labor, official, or business), and regular exercise habit

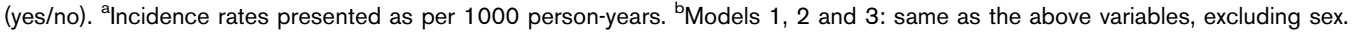

Fig. 1

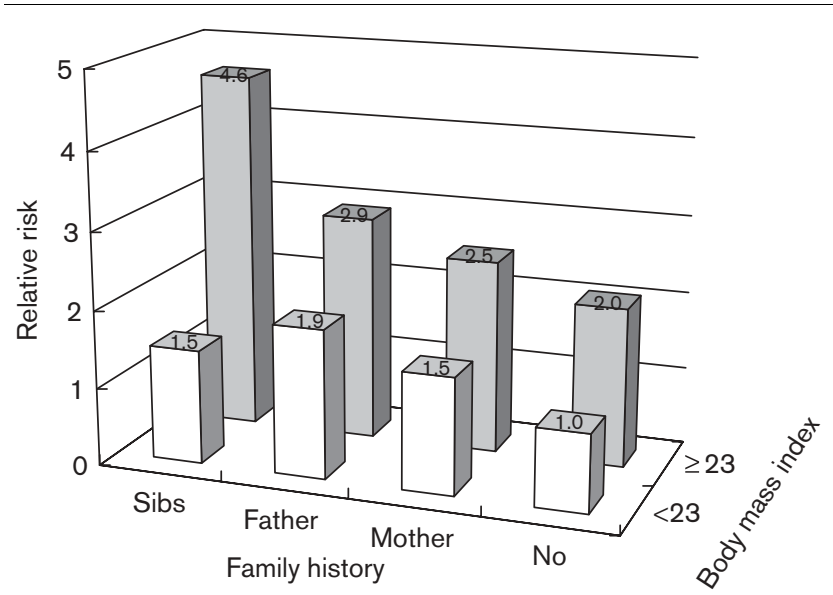

Relative risk of diabetes during the 9-year follow-up period according to various family history status and body mass index value (cutoff by median level, $23 \mathrm{~kg} / \mathrm{m}^{2}$ ), with adjustment for sex, alcohol intake, smoking, marital status, education, job status, and physical activity.

plicative interaction of BMI and family history on diabetes risk was observed (the likelihood ratio test, $P=0.61)$.

\section{Discussion}

In this prospective cohort of middle-aged to older ethnic Chinese, sibling history of diabetes was appreciably associated with increased risk of diabetes. Parental and maternal history appeared to be at least a predictor of diabetes. After adjustment for age, sex, and BMI, sibling history still has effects on diabetes risk. Age and higher BMI added significant risks of developing diabetes.
To our knowledge, this is the first extensive prospective investigation on various family histories and diabetes risk among ethnic Chinese. Our data showed that sibling history showed a higher risk than parental history, which is consistent with findings among hospital-based populations with diabetes [14]. Sibling recurrence risk is increased from 1.2 in participants without diabetic parents to 3.7 in those with both diabetic parents.

Biologically, there were several hypotheses to explain our findings. First, because of the complex mechanism of diabetes pathogenesis, sibling correlations for atherosclerotic traits are larger than parent-offspring correlations $[15,16]$. Second, sibling correlations were more important for heritability estimates than parent-offspring correlations. Sibling pairs have higher shared environmental factors than parent-offspring pairs and some common environments in young childhood have been postulated to be associated with future adult diseases [17]. However, although sibling history of diabetes might be useful as a screening tool, the information about potential pathophysiologic mechanisms underlying the associations is less valuable. First, our study participants had a large number of siblings (average 5.5), and we defined a positive sibling history as a self-report of history in at least one sibling. Second, we categorized the cases with both sibling and parent history $(\sim 2 \%)$ as sibling so that the risk of sibling history may be overestimated. Third, the diagnostic rates about sibling history may be higher due to awareness. Thus, it seems that sibling history of diabetes may be a proxy-marker of both environmental and genetic factors, and as a genetic marker probably more valid than parental history.

There exists different risk estimates across different ethnic populations, and the relative risks of parental 
history are around 1.2-3.5-fold; but, there are several undefined factors. First, evidence from the prospective cohort data provides different results [18-22]. Second, ethnicity has an effect on diabetes risks, and these risks are different across various ethnicities [23]. For Caucasians, a family history of diabetes has a 2.19-fold increase of diabetes in a more than 20 years of follow-up study [19]. Our data also showed that the relative risks were 1.4-2.1-fold, consistent with previous findings [24].

The hypothesis of excess maternal transmission in diabetes is still controversial [24]. The mechanisms of female predominance in terms of transmission were postulated as the unique maternal genetic and environmental effects [25], whereas gestational diabetes had strong effects on offspring diabetes risk [26]. Our data showed equal risks from maternal and paternal lineage. Other studies, including those of animals [27], as well as population-based data, show equal risks from both parents [28-30].

The high prevalence and increasing incidence of diabetes have made it an epidemic among ethnic Chinese [31]. Lee and colleagues collected information from 2310 patients with diabetes in Hong Kong and observed differential parental effects on diabetes risk [32]. Another cross-sectional study in Taiwan reported that maternal history only appeared among the younger age group ( $<65$ years) [33]. Our study, with a much larger sample size and prospective design, found a strong and significant association between sibling history and diabetes.

This study has several strengths. First, because of the prospective cohort design, the baseline measurements of all cohort members were unlikely to be affected by recall bias. Second, we included important socioeconomic status and lifestyle factors in the model to control the potential confounding factors. Finally, we ascertained incidences of diabetes by combining clinical medication history diagnosis and laboratory diagnosis. Our data suggested that sibling family history should be considered as a screening tool for risk stratification of developing diabetes [23].

\section{Study limitations}

This study had several limitations. First, because measurements were taken only once, the results might be prone to intraindividual variations, which might have attenuated the results. Second, lack of parent history on an individual's risk may be due to low diagnostic activity among parents. The diagnostic activity was lower decades ago and there may have been many unknown cases. Finally, we did not include cases by the oral glucose tolerance test, so the rates of incident cases may be underestimated.

\section{Conclusion}

Our study clearly demonstrated that sibling history is more strongly associated with the risk of diabetes than parental history among ethnic Chinese, whereas obesity increases the risk in all persons consistently. We suggested that sibling history be recorded for the comprehensive evaluation of diabetes in Asian populations.

\section{Acknowledgements}

The authors express their gratitude to the participants from the Chin-Shan community and the cardiologists at the National Taiwan University Hospital for their assistance in this study.

\section{References}

1 Anonymous. Report of the Expert Committee on the Diagnosis and Classification of Diabetes Mellitus. Diabetes Care 1997; 20:1183-1197.

2 Centers for Disease Control and Prevention (CDC). Awareness of family health history as a risk factor for disease-United States, 2004. MMWR Morb Mortal Wkly Rep 2004; 53:1044-1047.

3 Guttmacher AE, Collins FS, Carmona RH. The family history-more important than ever. N Engl J Med 2004; 351:2333-2336.

4 O'Donnell CJ. Family history, subclinical atherosclerosis, and coronary heart disease risk: barriers and opportunities for the use of family history information in risk prediction and prevention. Circulation 2004; 110: 2074-2076.

5 Hunt SC, Gwinn M, Adams TD. Family history assessment: strategies for prevention of cardiovascular disease. Am J Prev Med 2003; 24:136-142.

6 Yoon PW, Scheuner MT, Peterson-Oehlke KL, Gwinn M, Faucett A, Khoury MJ. Can family history be used as a tool for public health and preventive medicine? Genet Med 2002; 4:304-310.

7 Annis AM, Caulder MS, Cook ML, Duquette D. Family history, diabetes, and other demographic and risk factors among participants of the National Health and Nutrition Examination Survey 1999-2002. Prev Chronic Dis 2005; 2:A19.

8 Hariri S, Yoon PW, Qureshi N, Valdez R, Scheuner MT, Khoury MJ. Family history of type 2 diabetes: a population-based screening tool for prevention? Genet Med 2006; 8:102-108.

9 Goldfine AB, Beckman JA, Betensky RA, Devlin H, Hurley S, Varo N, et al. Family history of diabetes is a major determinant of endothelial function. J Am Coll Cardiol 2006; 47:2456-2461.

10 Chien KL, Hsu HC, Sung FC, Su TC, Chen MF, Lee YT. Hyperuricemia as a risk factor on cardiovascular events in Taiwan: the Chin-Shan Community Cardiovascular Cohort Study. Atherosclerosis 2005; 183:147-155.

11 Lee YT, Lin RS, Sung FC, Yang CY, Chien KL, Chen WJ, et al. Chin-Shan Community Cardiovascular Cohort in Taiwan: baseline data and five-year follow-up morbidity and mortality. J Clin Epidemiol 2000; 53:836-846.

12 Chien KL, Lee YT, Sung FC, Hsu HC, Su TC, Lin RS. Hyperinsulinemia and related atherosclerotic risk factors in the population at cardiovascular risk: a community-based study. Clin Chem 1999; 45 (6 Pt 1):838-846.

13 Hosmer DW Jr, Lemeshow S. The multiple logistic regression model. Applied logistic regression. 1st ed. New York: John Wiley \& Sons; 1989. pp. 25-37.

14 Weijnen CF, Rich SS, Meigs JB, Krolewski AS, Warram JH. Risk of diabetes in siblings of index cases with Type 2 diabetes: implications for genetic studies. Diabet Med 2002; 19:41-50.

15 Chien KL, Hsu HC, Chen WJ, Chen MF, Su TC, Lee YT. Familial aggregation of metabolic syndrome among the Chinese: report from the Chin-Shan community family study. Diabetes Res Clin Pract 2007; 76:418-424.

16 Chien KL, Hsu HC, Su TC, Lee YT. Consistency in genetic inheritance mode and heritability patterns of triglyceride vs. high density lipoprotein cholesterol ratio in two Taiwanese family samples. BMC J, Genetics 2003; 4:7-16.

17 Smith GD, Hart C, Blane D, Hole D. Adverse socioeconomic conditions in childhood and cause specific adult mortality: prospective observational study. Br Med J 1998; 316:1631-1635.

18 Mitchell BD, Valdez R, Hazuda HP, Haffner SM, Monterrosa A, Stern MP. Differences in the prevalence of diabetes and impaired glucose tolerance according to maternal or paternal history of diabetes. Diabetes Care 1993; 16:1262-1267. 
19 Bjornholt JV, Erikssen G, Liestol K, Jervell J, Thaulow E, Erikssen J. Type 2 diabetes and maternal family history: an impact beyond slow glucose removal rate and fasting hyperglycemia in low-risk individuals? Results from 22.5 years of follow-up of healthy nondiabetic men. Diabetes Care 2000; 23:1255-1259.

20 Burchfiel CM, Curb JD, Rodriguez BL, Yano K, Hwang $\sqcup$, Fong KO, Marcus EB. Incidence and predictors of diabetes in Japanese-American men. The Honolulu Heart Program. Ann Epidemiol 1995; 5:33-43.

21 Shaten BJ, Smith GD, Kuller LH, Neaton JD. Risk factors for the development of type II diabetes among men enrolled in the usual care group of the Multiple Risk Factor Intervention Trial. Diabetes Care 1993; 16:1331-1339.

22 Knowler WC, Pettitt DJ, Savage PJ, Bennett PH. Diabetes incidence in Pima Indians: contributions of obesity and parental diabetes. Am J Epidemiol $1981 ; 113: 144-156$.

23 Harrison TA, Hindorff LA, Kim H, Wines RC, Bowen DJ, McGrath BB, Edwards KL. Family history of diabetes as a potential public health tool. Am J Prev Med 2003; 24:152-159.

24 Lin RS, Lee WC, Lee YT, Chou P, Fu CC. Maternal role in type 2 diabetes mellitus: indirect evidence for a mitochondrial inheritance. Int J Epidemiol $1994 ; 23: 886-890$.

25 McCarthy M, Cassell P, Tran T, Mathias L, t Hart LM, Maassen JA, et al. Evaluation of the importance of maternal history of diabetes and of mitochondrial variation in the development of NIDDM. Diabet Med 1996; 13:420-428.
26 McLean M, Chipps D, Cheung NW. Mother to child transmission of diabetes mellitus: does gestational diabetes program Type 2 diabetes in the next generation? Diabet Med 2006; 23:1213-1215.

27 Gill-Randall RJ, Adams D, Ollerton RL, Alcolado JC. Is human Type 2 diabetes maternally inherited? Insights from an animal model. Diabet Med 2004; 21:759-762

28 Meigs JB, Cupples LA, Wilson PW. Parental transmission of type 2 diabetes: the Framingham Offspring Study. Diabetes 2000; 49: 2201-2207.

29 Kim DJ, Cho NH, Noh JH, Lee MS, Lee MK, Kim KW. Lack of excess maternal transmission of type 2 diabetes in a Korean population. Diabetes Res Clin Pract 2004; 65:117-124.

30 Mitchell BD, Kammerer CM, Reinhart LJ, Stern MP, MacCluer JW. Is there an excess in maternal transmission of NIDDM? Diabetologia 1995; 38:314-317.

31 Tseng $\mathrm{CH}$, Tseng CP, Chong CK, Huang TP, Song YM, Chou CW, et al. Increasing incidence of diagnosed type 2 diabetes in Taiwan: analysis of data from a national cohort. Diabetologia 2006; 49: 1755-1760.

32 Lee SC, Pu YB, Chow CC, Yeung VT, Ko GT, So WY, et al. Diabetes in Hong Kong Chinese: evidence for familial clustering and parental effects. Diabetes Care 2000; 23:1365-1368.

33 Sheu WH, Song YM, Lee WJ, Yao YE, Lin CJ, Tseng LN, et al. Family aggregation and maternal inheritance of Chinese type 2 diabetes mellitus in Taiwan. Zhonghua Yi Xue Za Zhi (Taipei) 1999; 62:146-151. 